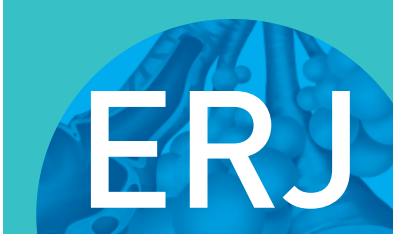

open research
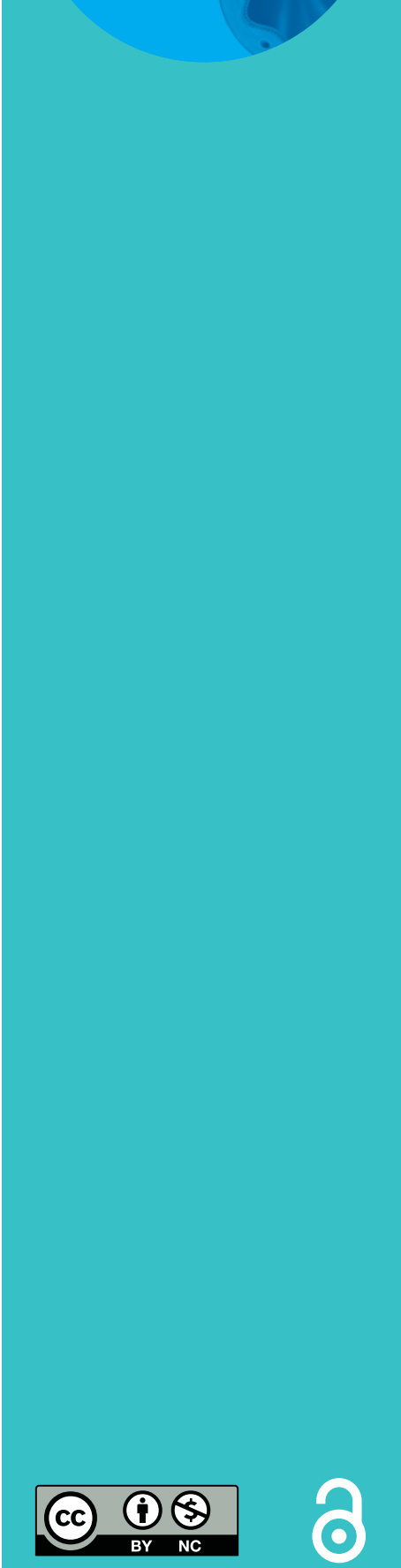

\section{The impact of changing to the Global Lung Function Initiative reference equations for transfer factor in paediatrics}

\author{
Paul D. Burns (1D ${ }^{1}$ and James Y. Paton ${ }^{1,2}$
}

Affiliations: ${ }^{1}$ Dept of Respiratory and Sleep Physiology, Royal Hospital for Children, Glasgow, UK. ${ }^{2}$ School of Medicine, College of Medical, Veterinary and Life Sciences, University of Glasgow, Glasgow, UK.

Correspondence: Paul Burns, Respiratory Function Laboratory, Royal Hospital for Children, 1345 Govan Road, Glasgow G51 4TF, UK. E-mail: paul.burns@gggc.scot.nhs.uk

ABSTRACT The Global Lung Function Initiative (GLI) all-age reference equations for carbon monoxide transfer factor were published in 2017 and endorsed by the European Respiratory Society and American Thoracic Society. In order to understand the impact of these new reference equations on the interpretation of results in children referred from haematology and oncology paediatric services, we retrospectively analysed transfer factor results from any paediatric patient referred from haematology/oncology in the period 2010-2018. We examined transfer factor of the lung for carbon monoxide $\left(T_{\mathrm{LCO}}\right)$, transfer coefficient of the lung for carbon monoxide $\left(K_{\mathrm{CO}}\right)$ and alveolar volume $\left(V_{\mathrm{A}}\right)$ from 241 children (age range 7-18 years, 130 male). The predicted values from Rosenthal and GLI were plotted against height. The difference in interpretation of results was analysed by looking at the percentage of patients below the lower limit of normal for each parameter. Overall, the Rosenthal predicted values for $T_{\mathrm{LCO}}$ were higher than those predicted by GLI. Predicted $K_{\mathrm{CO}}$ using Rosenthal was higher in all observations. In contrast, the Rosenthal predicted $V_{\mathrm{A}}$ was generally lower than the GLI value. The GLI predicted values for transfer factor show considerable differences compared with currently used paediatric UK reference values, differences that will have a significant impact on interpretation of results.

@ERSpublications

There will be significant clinical differences in the results of transfer factor when switching to the GLI-2017 from Rosenthal-1993 reference values, strongly recommending implementing the use of GLI-2017 reference equations for paediatrics https://bit.ly/3o0zR4f

Cite this article as: Burns PD, Paton JY. The impact of changing to the Global Lung Function Initiative reference equations for transfer factor in paediatrics. ERJ Open Res 2021; 7: 00412-2020 [https://doi.org/10.1183/23120541.00412-2020].

Received: 22 June 2020 | Accepted after revision: 21 Sept 2020

Copyright $\odot$ ERS 2021. This article is open access and distributed under the terms of the Creative Commons Attribution Non-Commercial Licence 4.0. 


\section{Introduction}

The European Respiratory Society (ERS) Global Lung Function Initiative (GLI) $T_{\text {LCO }}$ task force published all-age reference equations for the single-breath transfer factor test for carbon monoxide $\left(T_{\mathrm{LCO}}\right)$ in 2017 [1]. These were part of the GLI and have been endorsed by all major respiratory societies. These are now considered the gold-standard reference equations for transfer factor measurements and provide all age equations from age 4.5 to 85 years.

Prior to the development of the GLI standards, the most commonly used and widely referenced equations for $T_{\mathrm{LCO}}$ in paediatrics in the UK were from Rosenthal et al. [2]. These were based on 772 children and used simple regression. During puberty, lung function no longer increases proportionally to height, but rather follows a more complex pattern [3]; therefore, arbitrary cut-off points were used at a certain height for males and females that introduced a "step" in the predicted equation. This meant that when males reached a height of $162.6 \mathrm{~cm}$, they would move into a new regression equation for the calculation of their lung function parameters; for females the step occurred at $152.6 \mathrm{~cm}$. The authors did perform pubertal staging in $64 \%$ of their subjects and acknowledged that using two separate linear equations may lead to spurious changes in relative lung function for longitudinal assessment. Therefore, they recommended correcting for pubertal stage to minimise this. However, paediatric respiratory laboratories do not routinely pubertally stage their patients.

Before implementing these new reference values in the UK in paediatrics, it is important to look at the impact of changing to these new reference equations in a population of children where this measurement is often of clinical importance. Stem cell transplantation (SCT) and chemotherapy can cause impairment in lung function, which is often manifested by impaired alveolar gas transfer. Thus, the measurements of $T_{\mathrm{LCO}}$, transfer coefficient $\left(K_{\mathrm{CO}}\right)$ and alveolar volume $\left(V_{\mathrm{A}}\right)$ are particularly important for monitoring for the onset or progression of interstitial lung disease in this group of patients [4].

In this study, we aimed to determine the impact of the switch from Rosenthal equations to the GLI equations upon interpretation of transfer factor results in patients referred from a haematology/oncology service.

\section{Methods}

\section{Study design and patients}

Pulmonary function results from the Royal Hospital for Children (Glasgow, UK) were reviewed from 2010 to 2018. Ethics approval was not sought as this was a retrospective review of anonymised data. All patients who had been referred from haematology/oncology aged $<18$ years with a valid $T_{\text {LCO }}$ result according to the test meeting the criteria of the 1994 British Thoracic Society/Association of Respiratory Technologists and Physiologists lung function guidelines [5] were included. The results contained the actual measurements and the z-score based on Rosenthal reference equations [2]. The GLI online excel calculator provided by the ERS [6] was used to convert the predicted values and z-scores. The patient's sex, height and age were used. Height and age were taken to one decimal place. The z-score was then calculated using the test result data.

\section{Statistical analysis}

The predicted values for $T_{\mathrm{LCO}}, K_{\mathrm{CO}}$ and $V_{\mathrm{A}}$ were plotted against height using both reference sets for males and females. The mean difference and $95 \%$ confidence intervals between percentage predicted for the two reference ranges was calculated for all observations included in the dataset. Comparisons of z-scores for each parameter were analysed using Bland-Altman plots. This is a statistical way to evaluate a bias between the mean differences, and to estimate an agreement interval, within which $95 \%$ of the differences of the second method fall, compared to the first one [7]. The number of observations that were below the lower limit of normal for each parameter were directly compared for the two reference sets.

\section{Results}

241 patient test results were analysed; 130 male and 111 female. Of these test results, some were from the same patient on different dates as part of longitudinal follow-up. Table 1 shows the subject demographics. Height, weight and body mass index z-scores are calculated from the British 1990 growth reference data [8].

Figure 1a compares the predicted $T_{\mathrm{LCO}}$ values for Rosenthal and GLI in males and females when plotted against height. In the shorter patients, Rosenthal predicts higher values from $122 \mathrm{~cm}$ to $\sim 140 \mathrm{~cm}$ with some crossover at $140-145 \mathrm{~cm}$. From $145 \mathrm{~cm}$ to the pubertal breakpoint of $162.6 \mathrm{~cm}$, as defined in the Rosenthal paper, Rosenthal predicts lower values than GLI. After the arbitrary breakpoint, Rosenthal largely overpredicts the $T_{\mathrm{LCO}}$. Overall, the predicted values using Rosenthal were higher compared to GLI such that, on average, percentage predicted values were underestimated by $2.3 \%$ (95\% CI $2.1-2.7 \%$ ). 
TABLE 1 Demographic details of children referred from paediatric haematology/oncology services for measurement of transfer factor

$\begin{array}{lc}\text { Age years } & 13.2 \pm 2.7 \\ \text { Height } \mathbf{~ c m} & 151.5 \pm 13.6 \\ \text { Height z-score } & -0.5 \pm 1.3 \\ \text { Weight kg } & 46.3 \pm 13.8 \\ \text { Weight z-score } & -0.1 \pm 1.5 \\ \text { BMI z-score } & 0.2 \pm 1.5\end{array}$

Data are presented as mean \pm SD or range. BMI: body mass index.

In females, the Rosenthal values were systematically higher for $T_{\mathrm{LCO}}$, as shown in figure 1aii. There was no pubertal breakpoint in the $T_{\mathrm{LCO}}$ data for females. On average, percentage predicted values were underestimated by $5.8 \%$ (95\% CI 5.6-6.0\%) when compared to the GLI predicted values.

Figure $1 \mathrm{~b}$ shows the comparison of predicted $K_{\mathrm{CO}}$ values. There are some striking differences for both male and female. Rosenthal values were systematically higher compared to GLI in both male and female. Percentage predicted values were underestimated by $15.7 \%$ (95\% CI 15.4-16.1\%) and 20.9\% (95\% CI 20.4-21.5\%) in males and females, respectively.

Figure 1c shows the comparison of predicted $V_{\mathrm{A}}$ values. The opposite effect occurs from $T_{\mathrm{LCO}}$ and $K_{\mathrm{CO}}$, with Rosenthal predicted $V_{\mathrm{A}}$ values being systematically lower in males and females. The difference in males is more marked before the arbitrary pubertal break point with percentage predicted values being estimated as higher by $14.5 \%$ (95\% CI $14-15.1 \%)$ and $15.2 \%$ (95\% CI $14.5-15.8 \%)$ in males and females, respectively.

Figure 2 shows the Bland-Altman plots for comparison of the z-scores between the two reference sets for $T_{\mathrm{LCO}}, K_{\mathrm{CO}}$ and $V_{\mathrm{A}}$. Table 2 shows the summary of the mean differences and $95 \%$ limits of agreement.

Table 3 shows the difference in the percentage of patients whowould be classed as being below the lower limit of normal using either the Rosenthal or GLI predicted set for each parameter. For $T_{\mathrm{LCO}}, 39 \%$ of patients would have abnormal results using Rosenthal and 27\% using GLI. The same pattern occurred in the $K_{\mathrm{CO}}$, but there was a much wider discrepancy. $61 \%$ were below the lower limit of normal using Rosenthal and only $10 \%$ using GLI. The opposite occurred with $V_{\mathrm{A}}$ with only $10 \%$ of patients having a result below the lower limit of normal and $26 \%$ using GLI.

We looked at an individual case to demonstrate the effects of the different reference equations over time as part of longitudinal follow-up of patients. The patient was male and the first measurement was taken post-SCT when he was aged 12.6 years and $158.8 \mathrm{~cm}$ in height. The second measurement was taken 6 months later due to a relapse and prior to a repeat SCT. He was then $164.1 \mathrm{~cm}$, and therefore crossed the pubertal breakpoint in the Rosenthal equations. The results from both visits are shown in table 4 .

Looking at the patient's results using the Rosenthal reference values, the initial results show that the $T_{\mathrm{LCO}}$ and $K_{\mathrm{CO}}$ are at the low end of normal and the $V_{\mathrm{A}}$ is normal. However, the follow-up results show a significant deterioration in the $T_{\mathrm{LCO}}, K_{\mathrm{CO}}$ and $V_{\mathrm{A}}$, with all the values being below the lower limit of normal.

Using GLI, the initial results show a reduced $T_{\mathrm{LCO}}$ with a preserved, but not elevated, $K_{\mathrm{CO}}$ and a reduced $V_{\mathrm{A}}$. The follow-up results show a deterioration in $T_{\mathrm{LCO}}$ and $K_{\mathrm{CO}}$ and an improvement in $V_{\mathrm{A}}$.

\section{Discussion}

Comparison of the Rosenthal values with the new gold-standard GLI-2017 equations demonstrates several potential problems with using the Rosenthal values. Overall, Rosenthal produces higher predicted values for $T_{\mathrm{LCO}}$ in the majority of boys and in all girls. It also produces grossly higher predicted $K_{\mathrm{CO}}$ in all boys and girls. The opposite occurs in alveolar volume where Rosenthal produces systematically lower predicted values than GLI-2017 in boys and girls.

The difference in these predicted values for transfer factor has a significant clinical impact. Table 3 shows the differences in clinical interpretation for each parameter in our dataset. There were a greater number of patients who had a value below the lower limit of normal (a z-score $<-1.645$ ) for $T_{\mathrm{LCO}}$ and $K_{\mathrm{CO}}$ when using the Rosenthal predicted equations. The biggest difference was seen in the $K_{\mathrm{CO}}$ with the proportion of patients classed as having an "abnormal" measurement being 61\% using Rosenthal and only $10 \%$ when 
a)
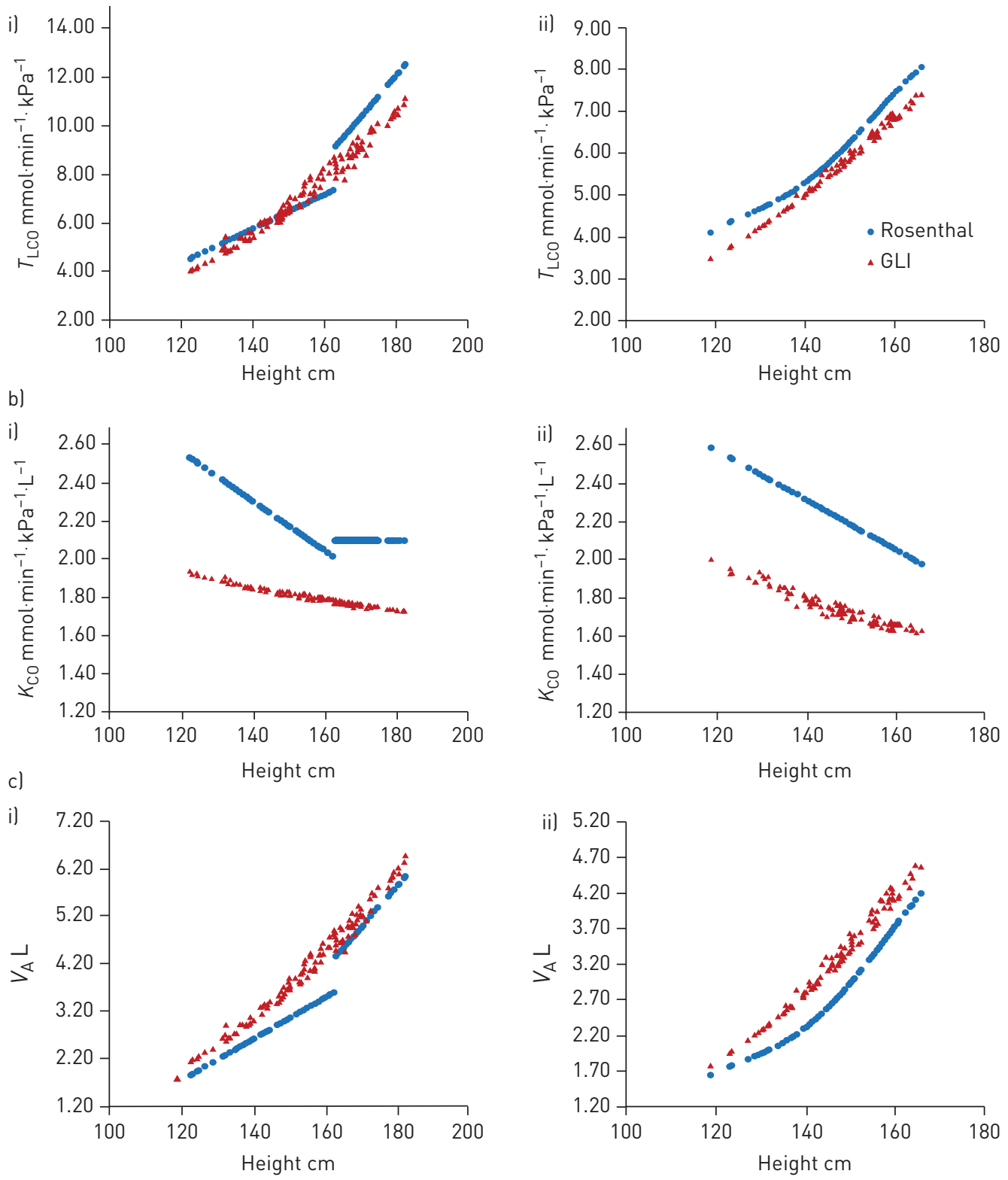

FIGURE 1 Predicted value using Rosenthal and Global Lung Function Initiative (GLI) equations plotted against height in i) males and ii) females for a) transfer factor of the lung for carbon monoxide ( $\left.T_{\mathrm{LCO}}\right)$; b) transfer coefficient of the lung for carbon monoxide $\left.\left(K_{\mathrm{CO}}\right) ; c\right)$ alveolar volume $\left(V_{\mathrm{A}}\right)$.

using GLI-2017. The opposite occurred with $V_{\mathrm{A}}$, with a greater proportion being classed as abnormal when using GLI-2017 compared to Rosenthal.

When measuring lung function in patients undergoing cancer treatment or SCT, the $T_{\mathrm{LCO}}$ is an important measurement for evaluating any potential lung damage caused by the treatment. The $K_{\mathrm{CO}}$ measures the rate of transfer of carbon monoxide from alveolar gas to the pulmonary blood, and therefore gives information on potential alveolar-capillary damage and diffusion impairment [9]. For this reason, $K_{\mathrm{CO}}$ is an important marker of lung function in such patients. We have shown that using the Rosenthal equations will lead to a gross overdiagnosis of lung dysfunction.

The results showed that the mean difference in the $T_{\mathrm{LCO}} \mathrm{z}$-scores between the Rosenthal and GLI reference values was quite small. However, there was a large mean difference in the $K_{\mathrm{CO}}$ and the $V_{\mathrm{A}}$ $\mathrm{z}$-scores, indicating that the Rosenthal values are overpredicting $K_{\mathrm{CO}}$ and underpredicting $V_{\mathrm{A}}$ in relation to the GLI predicted values. The reasons for this discrepancy can only be speculated. One possibility is the differences in equipment and gas analysis since the Rosenthal equations were published compared to the 
a)

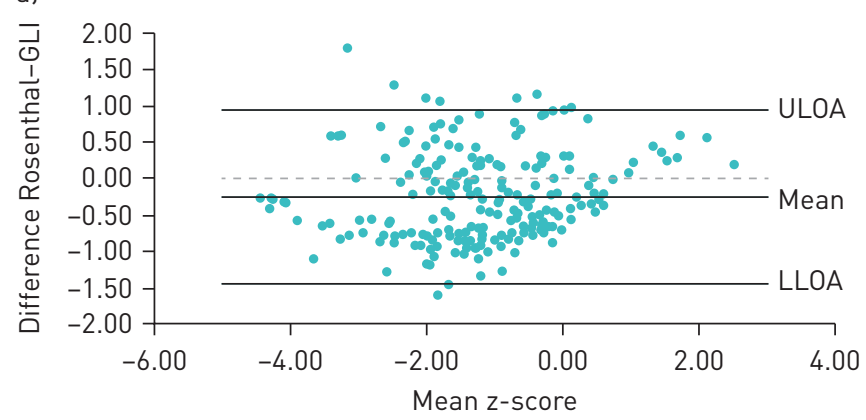

c)

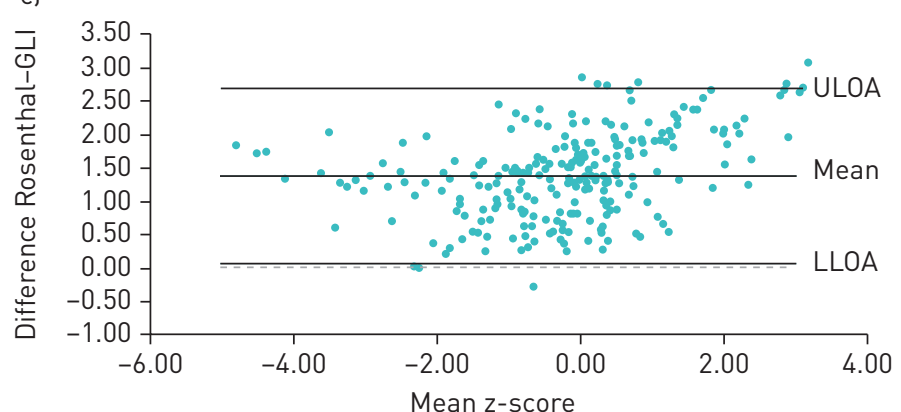

b)

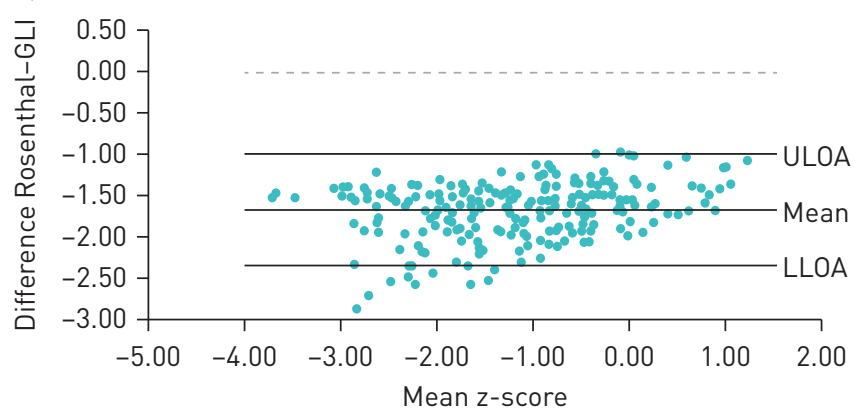

FIGURE 2 Bland-Altman plot comparing z-scores using Rosenthal and Global Lung Function Initiative (GLI) reference equations for a) transfer factor of the lung for carbon monoxide $\left(T_{\mathrm{LCO}}\right)$, b) transfer coefficient of the lung for carbon monoxide $\left(K_{\mathrm{CO}}\right)$ and $\left.\mathrm{C}\right)$ alveolar volume $\left(V_{\mathrm{A}}\right)$. ULOA: upper limits of agreement; LLOA: lower limits of agreement.

datasets used in the GLI. The GLI reference values dataset did not include the Rosenthal data because these data were collected on analysers that were made prior to 2000, which was the cut-off for contemporary data collection. The Rosenthal study used a Morgan body box. Modern systems such as rapidly responding gas analysers which use a different test gas and different algorithms may have contributed to the large differences seen between the two datasets.

Despite the Rosenthal equations being applicable across the age range from 6 to 18 years, in males particularly, the arbitrary breakpoint at the height cut-off of $162.4 \mathrm{~cm}$ may cause significant misinterpretation of results when looking at patient trend data across this height cut-off. We have shown this to be the case in our results. We looked at an individual subject who had transfer factor post-SCT. His results using Rosenthal were within the normal range and did not look concerning. He had repeat measurements 6 months later due to SCT failure with the view to having a second transplant. He had grown by $5.3 \mathrm{~cm}$ in height. His results on his second test showed a significantly reduced $T_{\mathrm{LCO}}$ and $K_{\mathrm{CO}}$ with a slightly reduced $V_{\mathrm{A}}$, which would indicate a rapid decline and abnormal gas transfer. However, using GLI, his initial test results were abnormal with a significantly reduced $T_{\mathrm{LCO}}, V_{\mathrm{A}}$ and preserved $K_{\mathrm{CO}}$ indicating impaired gas transfer with a slight decline 6 months later. The difference in these two sets of results could have impacted significantly on this patient's treatment regimen. Additionally, many adolescent patients will be followed-up into early adulthood and their measurements will be referenced against another reference equation when they reach age 18 years. The GLI-2017 equations have the

\section{TABLE 2 Comparison of z-scores using Rosenthal and Global Lung Function Initiative (GLI)} reference sets

\begin{tabular}{lcccc} 
& Rosenthal z-score & GLI z-score & Mean difference Rosenthal-GLI & 95\% LOA \\
\hline$T_{\text {Lco }}$ & $-1.33 \pm 1.3$ & $-1.06 \pm 1.2$ & $-0.27(-0.3--0.2)$ & $-1.4-0.9$ \\
$K_{\text {co }}$ & $-1.98 \pm 1.1$ & $-0.31 \pm 1.0$ & $-1.67(-1.7--1.6)$ & $-2.3--1.0$ \\
$V_{\mathbf{A}}$ & $0.39 \pm 1.6$ & $-0.99 \pm 1.4$ & $1.38(1.3-1.5)$ & $0.1-2.7$ \\
\hline
\end{tabular}

Data are presented as mean \pm SD or mean difference $(95 \% \mathrm{CI})$, unless otherwise stated. LOA: limits of agreement; $T_{\mathrm{LCO}}$ : transfer factor of the lung for carbon monoxide; $K_{\mathrm{CO}}$ : transfer coefficient of the lung for carbon monoxide; $V_{\mathrm{A}}$ : alveolar volume. 
TABLE 3 Percentage of patients who have a $z$-score $<-1.645$ for each reference set

\begin{tabular}{lccc}
\hline Predicted set & $\boldsymbol{T}_{\text {Lco }}$ & $\boldsymbol{K}_{\mathbf{c o}}$ & $\boldsymbol{V}_{\mathbf{A}}$ \\
\hline $\begin{array}{l}\text { Rosenthal \% <LLN } \\
\text { GLI \% <LN }\end{array}$ & 40 & 61 & 11 \\
& 27 & 10 & 27 \\
\hline $\begin{array}{l}T_{\text {Lco: }} \text { transfer factor of the lung for carbon monoxide; } K_{\text {co: }} \text { transfer coefficient of the lung for carbon } \\
\text { monoxide; } V_{\mathrm{A}} \text { : alveolar volume; GLI: Global Lung Function Initiative; LLN: lower limit of normal. }\end{array}$
\end{tabular}

\begin{tabular}{|c|c|c|c|c|c|}
\hline & $\begin{array}{l}\text { Rosenthal } \\
\text { predicted }\end{array}$ & $\begin{array}{c}\text { GLI } \\
\text { predicted }\end{array}$ & Measured & $\begin{array}{l}\text { Rosenthal } \\
\text { z-score }\end{array}$ & $\begin{array}{c}\text { GLI } \\
\text { z-score }\end{array}$ \\
\hline \multicolumn{6}{|l|}{ Visit 1} \\
\hline$T_{\mathrm{LCO}} \mathrm{mmol} \cdot \mathrm{min}^{-1} \cdot \mathrm{kPa}^{-1}$ & 7.13 & 7.50 & 5.23 & -1.56 & -2.27 \\
\hline$K_{\text {CO }} \mathrm{mmol} \cdot \mathrm{min}^{-1} \cdot \mathrm{kPa}^{-1} \cdot \mathrm{L}^{-1}$ & 2.07 & 1.79 & 1.71 & -1.57 & -0.31 \\
\hline$V_{\mathrm{A}} \mathrm{L}$ & 3.43 & 4.25 & 3.07 & -0.95 & -2.56 \\
\hline \multicolumn{6}{|l|}{ Visit 2} \\
\hline$T_{\text {LCo }} \mathrm{mmol} \cdot \mathrm{min}^{-1} \cdot \mathrm{kPa}^{-1}$ & 9.39 & 8.22 & 5.29 & -2.51 & -2.74 \\
\hline$K_{\mathrm{CO}} \mathrm{mmol} \cdot \mathrm{min}^{-1} \cdot \mathrm{kPa}^{-1} \cdot \mathrm{L}^{-1}$ & 2.1 & 1.78 & 1.50 & -2.60 & -1.13 \\
\hline$V_{\mathrm{A}} \mathrm{L}$ & 4.44 & 4.66 & 3.52 & -1.89 & -2.26 \\
\hline
\end{tabular}

advantage of providing a single reference set from age 4.5 to 85 years, providing uniform clinical interpretation of trend data in patients undergoing long-term follow-up and avoiding any discontinuity arising from arbitrary cut-offs or changes in reference equations.

It has now been shown that linear regression has significant limitations when used for modelling lung function throughout life and more advanced statistical methods, such as the lambda-mu-sigma method, are required to generate adequate reference ranges [10]. The major limitations of the Rosenthal values were that only height and sex were used to develop the equations. Age was not considered, and simple additive linear regression techniques were used.

Previous research has looked at the impact of changing to GLI reference equations for spirometric parameters [11]. They showed that the discrepancies were largest in young children and adolescents. This is similar to what we have found for transfer factor. Future research should look at the impact of switching to the GLI-2017 equations in the adult population, where the measurement of transfer factor will occur more frequently.

In summary, the Rosenthal predicted equations for transfer factor are likely to lead to significant misinterpretation of the results in paediatric patients. The GLI-2017 reference equations are all-age equations, developed using complex statistical methods that account for growth and development of the lungs across the transition from child to adolescent to adult with no arbitrary break points. We recommended that the GLI-2017 reference equations are adopted to improve interpretation of lung function results. When switching to these reference equations, the clinical team should be educated on the differences that are likely to be seen and made aware of the potential clinical impact. This will be particularly important when trending results. Therefore, we would recommend that all retrospective results should be recalculated using the GLI equations before evaluating the trend report.

Conflict of interest: None declared.

\section{References}

1 Stanjoevic S, Graham BL, Cooper BG, et al. Official ERS technical standards: Global Lung Function Initiative reference values for the carbon monoxide transfer factor for Caucasians. Eur Respir J 2017; 50: 1700010.

2 Rosenthal M, Cramer D, Bain SH, et al. Lung function in white children aged 4 to 19 years: II - single breath analysis and plethysmography. Thorax 1993; 48: 803-808.

3 Nève V, Girard F, Flahault A, et al. Lung and thorax development during adolescence: relationship with pubertal status. Eur Respir J 2002; 20: 1292-1298. 
4 Gower AW, Collaco MJ, Mogayzel PJ Jr. Lung function and late pulmonary complications among survivors of hematopoietic stem cell transplantation during childhood. Paediatr Respir Rev 2010; 11: 115-122.

5 Guidelines for the measurement of respiratory function. Recommendations of the British Thoracic Society and the Association of Respiratory Technologists and Physiologists. Respir Med 1994; 88: 165-194.

6 Global Lung Function Initiative. ERS E-Learning resources, Guidelines, Global Lung Function Initiative TL,CO Tools Online Calculator. Available from: www.ers-education.org/guidelines/global-lung-function-initiative/tl-cotools/online-calculator/

7 Altman DG, Bland JM. Measurement in medicine: the analysis of method comparison studies. Statistician 1983; 32: $307-317$

8 Cole TJ, Freeman JV, Preece MA. British 1990 growth reference centiles for weight, height, body mass index and head circumference fitted by maximum penalized likelihood. Stat Med 1998; 17: 407-429.

9 Hughes JMB. The single breath transfer factor $\left(T_{\mathrm{L}, \mathrm{co}}\right)$ and the transfer coefficient $\left(K_{\mathrm{CO}}\right)$ : a window onto the pulmonary microcirculation. Clin Physiol Funct Imaging 2003; 23: 63-71.

10 Cole TF, Green PJ. Smoothing reference centile curves: the LMS method and penalized likelihood. Stat Med 1992; 11: $1305-1319$.

11 Stanjoevic S, Stocks J, Bountziuka V, et al. The impact of switching to the new global lung function initiative equations on spirometry results in the UK CF registry. J Cyst Fibros 2014; 13: 319-327. 